\title{
Coral reef monitoring in Tanzania: an analysis of the last 20 years
}

\author{
Christopher A. Muhando \\ Institute of Marine Sciences, University of Dar es Salaam, P.O. Box 668 Zanzibar, TANZANIA.
}

Keywords: coral reefs, community-based monitoring, Tanzania.

\begin{abstract}
Coral reef monitoring in Tanzania started in the early 1990s. The main objective was to document reef status and in places assess the extent of damage caused by the use of destructive resource harvesting practices, mainly fishing using dynamite and dragged nets. The information obtained formed the basis for setting up of legislation and control measures and for further monitoring of reef health. Two systems evolved: low tech or simple (skin diving) community-based coral reef monitoring and high tech involving the use of Self Contained Underwater Breathing Apparatus (SCUBA). Coral reef monitoring (CRM) has contributed substantial descriptive information and has raised awareness to coastal communities and managers. Analysis of CRM data over the years has provided information on the dynamics of reef health conditions, e.g. cover and composition of reef benthos, fish and macro-invertebrates. Statistical Power Analysis tests, both on spatial and temporal scales showed inadequate coral monitoring sampling effort, mainly due to high variance of categories being measured. Furthermore, the ongoing monitoring programs did not include environmental or economic indicator variables, hence monitoring results were not linked or statistically analysed against possible causative factors. Lack of information on biological connectivity and vital replenishment factors, e.g., larval sources, dispersal mechanisms, growth, and survival also diluted the interpretation of benthic community data, directly impacting on the strategic management of reef fish and invertebrates. Similarly, the link between socio-economic attributes and coral monitoring results has remained weak. This paper discusses critical issues in the past coral reef monitoring programs and provides strategic recommendations for the next phase of coral reef monitoring in Tanzania.
\end{abstract}

\section{INTRODUCTION}

Coral reefs provide the basis for artisanal fisheries (Jiddawi and Stanley, 1997; Johnstone et al., 1998; Ireland et al., 2004), coastal tourism (TCMP, 2001) and extraction of natural products (Scheuer, 2006). The complexity of reef environment is crucial in the preservation of biodiversity and the protection of coastal zones. However, the economic value and their proximity make coral reefs vulnerable to overexploitation and degradation, e.g., over-fishing, destructive fishing, trampling, anchor damage, coral mining, coastal construction and pollution (Muhando et al., 2004; Wagner, 2004). As in other parts of the world (Wilkinson, 2004; Souter and Linden, 2005), reefs in Tanzania 
are at risk from climate change, which appear to aggravate coral bleaching events (McClanahan et al., 2007a), fleshy algal and corallimorpharia proliferation (McClanahan et al., 2001; Muhando et al., 2002), coral disease (Raymundo et al., 2008) and crown-of-thornsstarfish infestation (Ussi, 2008). Taking into consideration the value and stress factors on coral reefs, it is imperative to be continuously aware of their status as without information from such monitoring programs, management practices cannot be implemented.

Coral Reef Monitoring (CRM) is the gathering of data and information on coral reef ecosystems and its users on a regular basis. According to Wilkinson et al. (2003), monitoring can be programmed to provide information on: a) resource (health) and threat status and long-term trends; b) status and long-term trends of users; c) impacts of large-scale disturbances, e.g. 1998 coral bleaching event; d) intensity and impacts of human activities; e) performance evaluation and adaptive management; f) education and awareness raising; g) contributing to regional and global networks; h) resource assessment and mapping; and i) growth and impacts of tourism in a given area. The gathering of such information involves a number of monitoring methods, often over a range of scales from the whole reef to a smaller area.

The existing monitoring programs in Tanzania concentrated mostly on biophysical monitoring (Horrill et al., 1994a; Muhando, 1999; Mohammed et al., 2000, 2002). Socioeconomic monitoring of coral reefs has only recently started (e.g. Malleret-King et al., 2006).

\section{BIOPHYSICAL MONITORING OF CORAL REEFS IN TANZANIA: PROGRESSION}

The objective of initiating coral reef monitoring programs was to assess the extent of reef damage caused by the use of destructive resource harvesting practices. Efforts towards establishing coral reef monitoring in Tanzania started in early 1990s. Baseline studies were carried out first (e.g., UNEP, 1989; Ngoile, 1990; Horrill and Ngoile, 1991; Horrill et al., 1994a, 1994b; Muhando, 1995). Results of these constituted the basis for establishing new fisheries legislations, including deciding on locations of MPAs and monitoring sites in Tanzania.

The first attempt to set up permanent coral reef monitoring transects was in Zanzibar (Ngoile, 1990) and Mafia (Horrill and Ngoile, 1991). However, repeated sampling was not successful until 1994 when the Institute of Marine Sciences, with support from CIDA-Canada and Sida-SAREC (Sweden) formed a SCUBA Based Coral Reef Monitoring (SB-CRM) team. Permanent plots and transects were first established off Zanzibar town reefs, in Menai Bay and Mnemba in Unguja, and in Misali in Pemba (Fig. 1).

Due to high costs involved in coral reef monitoring using SCUBA, i.e. air compressor (US\$ 6,800), dive tanks (each about US\$ 400 ), regulators (US\$ 350), buoyancy control devices (US\$ 400), weight-belts (US\$ 20), dive computers (US\$ 500), in addition to servicing of these items, the Tanga Coastal Zone Conservation and Development Program (TCZCDP) established a community-based coral reef monitoring (CB-CRM) which uses only snorkel, mask and fins. Instead of relying on scientists, CB-CRM trained District Fisheries Officers and local fishers in 1996 to undertake the monitoring, with significant economic savings yet providing useful data (Horrill et al., 2001). Following what later proved to be a successful trial for the TCZCDP program (see Wells et al., 2007), the Kinondoni Coastal Area Management Project (KICAMP) in collaboration with Faculty of Aquatic Sciences (FAST) initiated a similar CB-CRM program in Dar es Salaam (see Wagner, 2004). In 2004, the Tanzania Coastal Management Partnership (TCMP) program assisted Bagamoyo Natural Resources office to establish a community-based coral reef monitoring group in Bagamoyo (Mbije, 2005; Muhando, 2006). Efforts are underway to establish similar CB-CRM programs in Kilwa. 


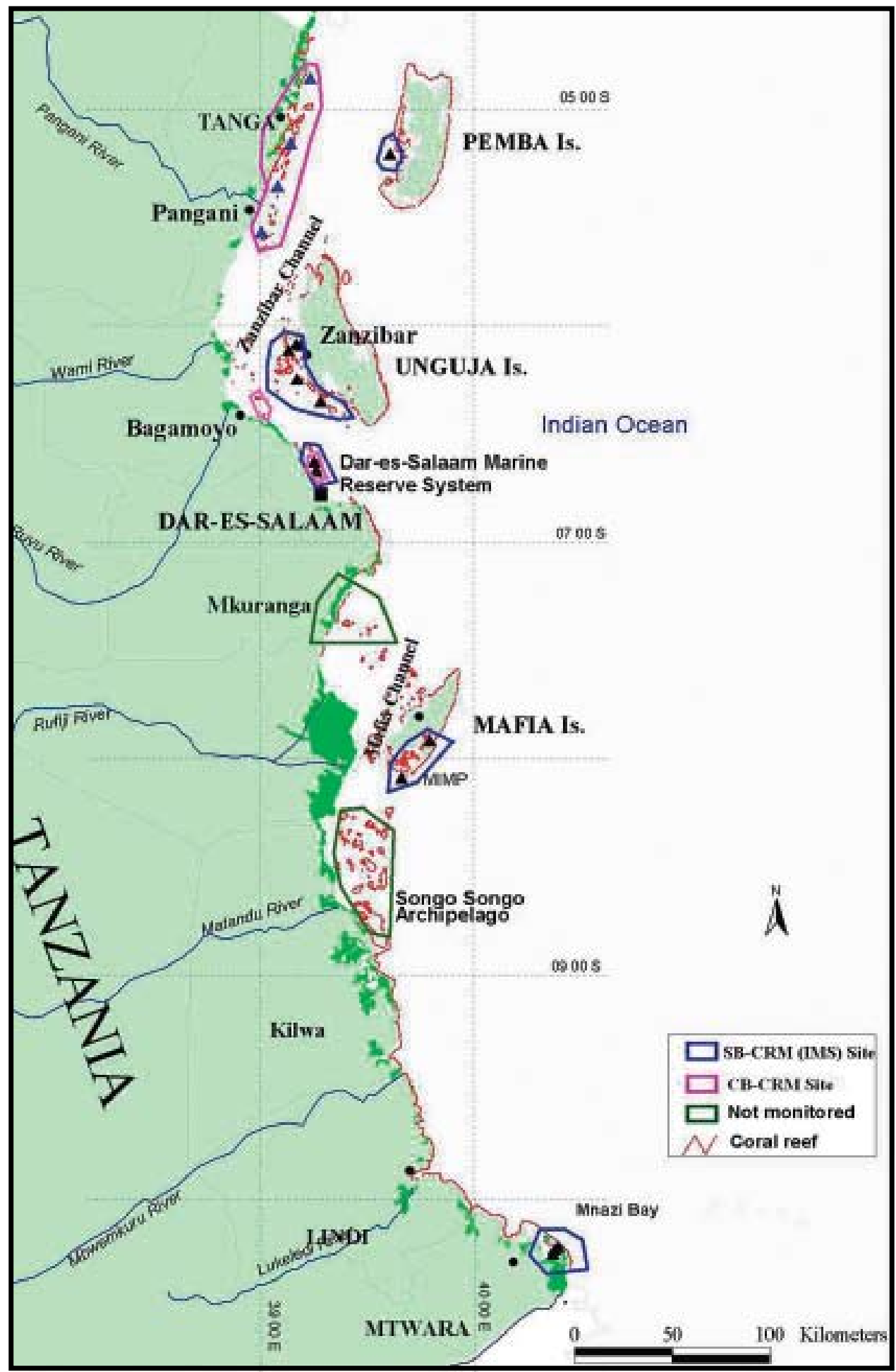

Fig. 1. Map showing the distribution of Community-Based Coral Reef Monitoring (CB-CRM) and Scuba Based Coral Reef Monitoring (SB-CRM) sites 
While the CB-CRM programs are expanding, only the Institute of Marine Sciences team is using the more costly SB-CRM approach.

Community-based monitoring program advantages include: cost effectiveness to cover large areas; useful as an 'early warning system' for changes in coral reef resources; and, education and awareness enhancement and local ownership of resources through the participation of community members. Limitations of community monitoring includes: low precision; a large amount of time must be spent on training (ongoing) to ensure reliable data; and reduced details.

After the 1998 coral bleaching event, new coral reef monitoring sites were initiated in 1999 in Dar es Salaam, Mafia and Mtwara making a total of 12 sites (five in Unguja, one in Pemba, two in Dar es Salaam, two in Mafia and two in Mtwara), all being monitored by SB-CRM with 10 sites monitored using CBCRM (five in Tanga, three in Bagamoyo and two in Dar es Salaam) (Fig. 1).

Table 1. Coral Reef benthic categories monitored by CB-CRM and SB-CRM Programs

\begin{tabular}{|c|c|c|}
\hline & SB-CRM (Institute of Marine Sciences) & CB-CRM (Tanga) \\
\hline OBJECT TYPE & BENTHIC OBJECTS (OBJECT ID) & BENTHIC OBJECTS (OBJECT ID) \\
\hline $\begin{array}{l}\text { Live hard corals } \\
\text { (HC) }\end{array}$ & $\begin{array}{l}\text { Acropora, branching (ACB) } \\
\text { Acropora, encrusting (ACE) } \\
\text { Acropora, submassive (ACS) } \\
\text { Acropora, digitate (ACD) } \\
\text { Acropora, tabulate (ACT) } \\
\text { Coral, branching (CB) } \\
\text { Coral, encrusting (CE) } \\
\text { Coral, foliose (CF) } \\
\text { Coral, massive (CM) } \\
\text { Coral, submassive (CS) } \\
\text { Coral, mushroom (CMR) } \\
\text { Coral, millepora (CME) } \\
\text { Coral, heliopora (CHL) }\end{array}$ & Matumbawe hai $(\mathrm{MH})$ \\
\hline Soft corals (SC) & Soft coral $(\mathrm{SC})$ & Matumbawe laini (ML) \\
\hline Sponges (SP) & Sponges (SP) & Spongi (SP) \\
\hline & Coralline algae (CA) & \\
\hline Algae (AL) & $\begin{array}{l}\text { Algal assemblage (AA) } \\
\text { Algae, Halimeda (HA) } \\
\text { Algae, Macroalgae (MA) } \\
\text { Algae, Turf algae (TA) }\end{array}$ & Mwani (MN) \\
\hline & Seagrass (SG) & Majani (MJ) \\
\hline Others (OT) & $\begin{array}{l}\text { Zoanthids (ZO) } \\
\text { Clam (CLAM) } \\
\text { Corallimorpharian (RH) } \\
\text { Others (OT) }\end{array}$ & Others (OT) \\
\hline \multirow{4}{*}{ Substrate (SU) } & Sand (S) & Mchanga (MC) \\
\hline & Silt (SI) & \\
\hline & Rock (RCK) & Mwamba (MW) \\
\hline & $\begin{array}{l}\text { Rubble }(\mathrm{R}) \\
\text { Dead coral (DC) } \\
\text { Dead coral with algae (DCA) }\end{array}$ & Matumbawe yaliyokufa (MK) \\
\hline
\end{tabular}




\section{CORAL REEF MONITORING METHODS}

Both CB-CRM and SB-CRM methods are based on internationally recognized protocols developed in Southeast Asia (English et al., 1997). Reef benthos (live coral cover, coralline algae, soft corals, sponges, fleshy algae, non-biotic cover) are assessed using the Line-Intercept transect method, while reef fish and macro-invertebrates (lobsters, clams, gastropods, sea urchins, sea cucumbers, sea stars, crown-of-thorns-starfish) are counted in belt transects. The CB-CRM Program grouped all live hard corals as one category "Matumbawe Hai" and all algal types in one category "Mwani" while SB-CRM used 13 coral growth form categories (Table 1). Coralline algae were separated from turf, macro-algae, Halimeda and other algal assemblages in SB-CRM, while reef fish and macro-benthos health indicators were similar (Table 1).

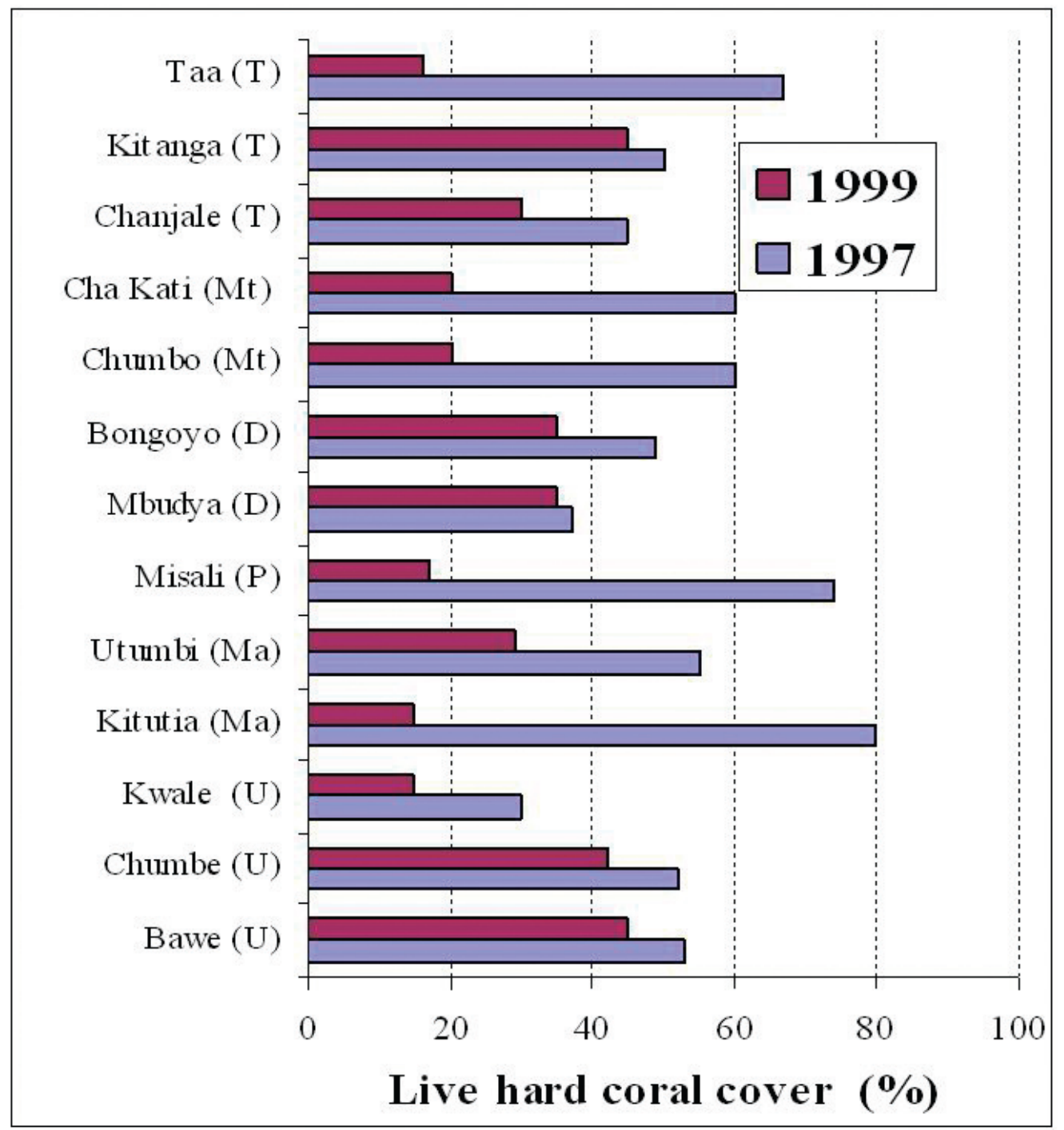

Fig. 2. The impact of the 1998 coral bleaching event on coral cover (1997 vs 1999) in various reef sites in Tanzania $(T=$ Tanga, $M t=$ Mtwara, $D=$ Dar es Salaam, Ma $=$ Mafia, $P=$ Pemba and $\mathrm{U}=$ Unguja, Zanzibar) 


\section{CONTRIBUTIONS AND LESSONS LEARNT}

\section{Contribution to Integrated Coastal Management activities}

Results from coral reef monitoring contributed extensive and useful information on the intensity and trends of damage to coral reefs, including the extent and impact of the 1998 coral bleaching and mortality event, e.g. Fig. 2. Other coral monitoring results have already been published (Muhando, 1999; Mohammed et al., 2000, 2002; Muhando and Mohammed, 2002; Muhando et al., 2002). An example of long term trends in coral cover for two sites, Chumbe and Bawe in Zanzibar are shown in Fig. 3a and 3b. The loss of Acropora cover from 2004 to 2008 was due to crown-ofthorns-starfish outbreak in Bawe (Ussi, 2008) and the sudden drop in coral cover in Chumbe in 1999 was due to the coral bleaching event. Through coral reef monitoring, reef locations and coral species that suffered high mortality, e.g., Kitutia, Mafia and Misali, Pemba (Fig. 2), were identified and compared with other sites in the Western Indian Ocean region (McClanahan et al., 2007b).

Local knowledge on the coral reef environment and its resource was expanded specifically where community-based coral reef monitoring was practiced (Horrill et al., 2001). Better understanding was noted when monitoring results were disseminated by a trained monitor who is also a fellow community member (Wells et al., 2007). After understanding CRM reports, ICM managers became more aware of environmental processes and resource dynamics (Obura, 2004; Muhando, 2006). This understanding increased the desire for further information on factors driving the observed change. Resource protection efforts increased as a result of awareness derived from CRM programs, e.g. the establishment of the Collaborative Fisheries Management Plan in Bagamoyo, July 2005 - July 2006 and recently, the acceptance without reservations of local communities in
Kigombe-Sahare, Tanga to have their coastal zone be part of the new Coelacanth MPA.

Thepresentcontribution to theinternational forum (e.g., to GCRMN, UNEP, World Coral Reef Status Reports and CORDIO reports) is now more elaborate and detailed than before (e.g. Muhando, 2008a). Scientific knowledge on biodiversity, especially corals and reef fish species has improved tremendously (e.g. Richmond, 1997), specifically after the introduction of underwater photography; (Johnstone et al., 1998). The use of Kiswahili names is now popular among local communities in Tanzania (Mohamed et al., 2007) and efforts are underway to standardise local names of coral reef organisms.

Furthermore, coral reef monitoring raised issues that require more research. For example, commercially important reef macroinvertebrates such as lobsters, sea cucumbers and ornamental gastropods occurred in lower densities than anticipated in most reefs (Fig. 4; Mohammed et al., 2000, 2002). This decline is alarming and is attributed to various natural and human disturbances, including local overfishing and habitat destruction (Muhando et al., 2004), leading to interference in settlement and recruitment processes, resulting in low availability of larvae, poor settlement success, lack of suitable settlement surfaces, poor growth and survival rates and eventually low stock density and stagnant or decreasing harvest levels, hence reduced contribution to the economy of coastal communities. Besides the elimination of destructive fishing methods, studies on larval connectivity (source, dispersal routes, and recipient reef characteristics) are required to reveal larval dispersal processes and associated management options for important invertebrates, including positioning of new MPAs.

\section{Lesson learnt}

Coral reef monitoring data was characterised by high sample variances (Table 2). Higher variance requires higher sample sizes to increase the power to detect changes. Power Analysis of the coral reef monitoring data 


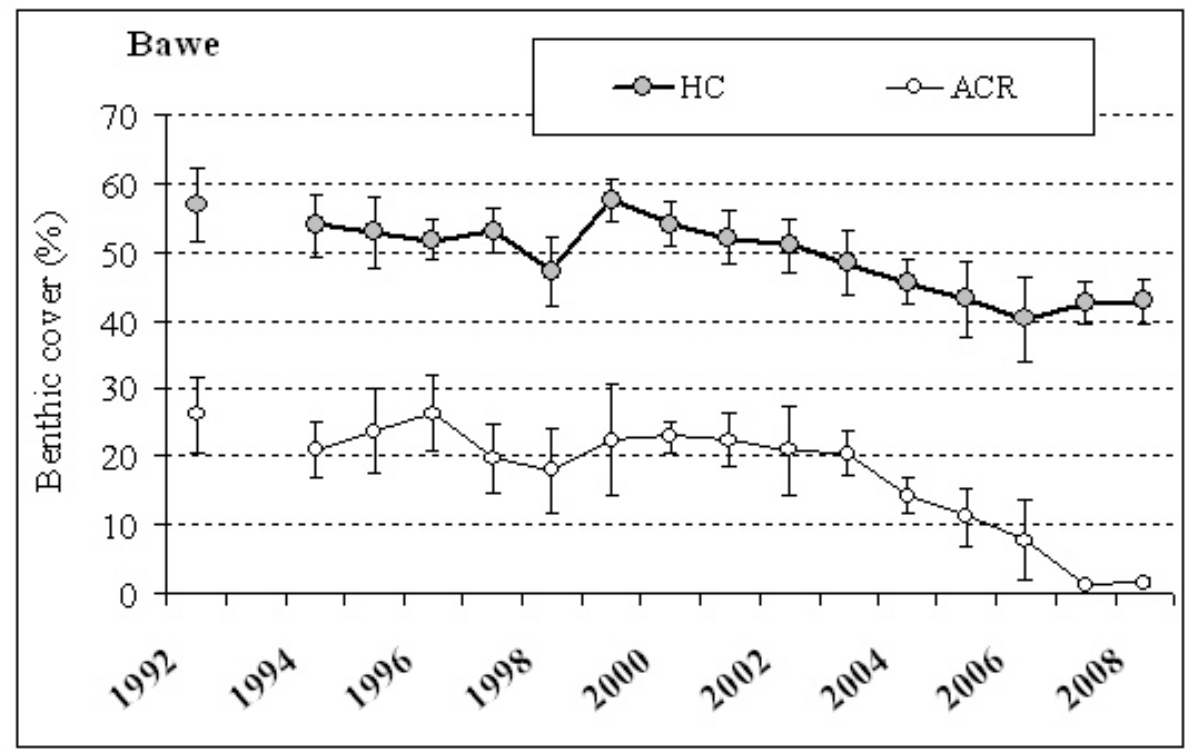

Fig. 3a. Long term trends in total live coral (HC) and Acropora cover in Bawe, Zanzibar. Note: Slight decline in 1998/99 was due to bleaching event and the decline in Acropora cover from 2002 to 2008 is due to outbreak of Crown-of-thorns-starfish

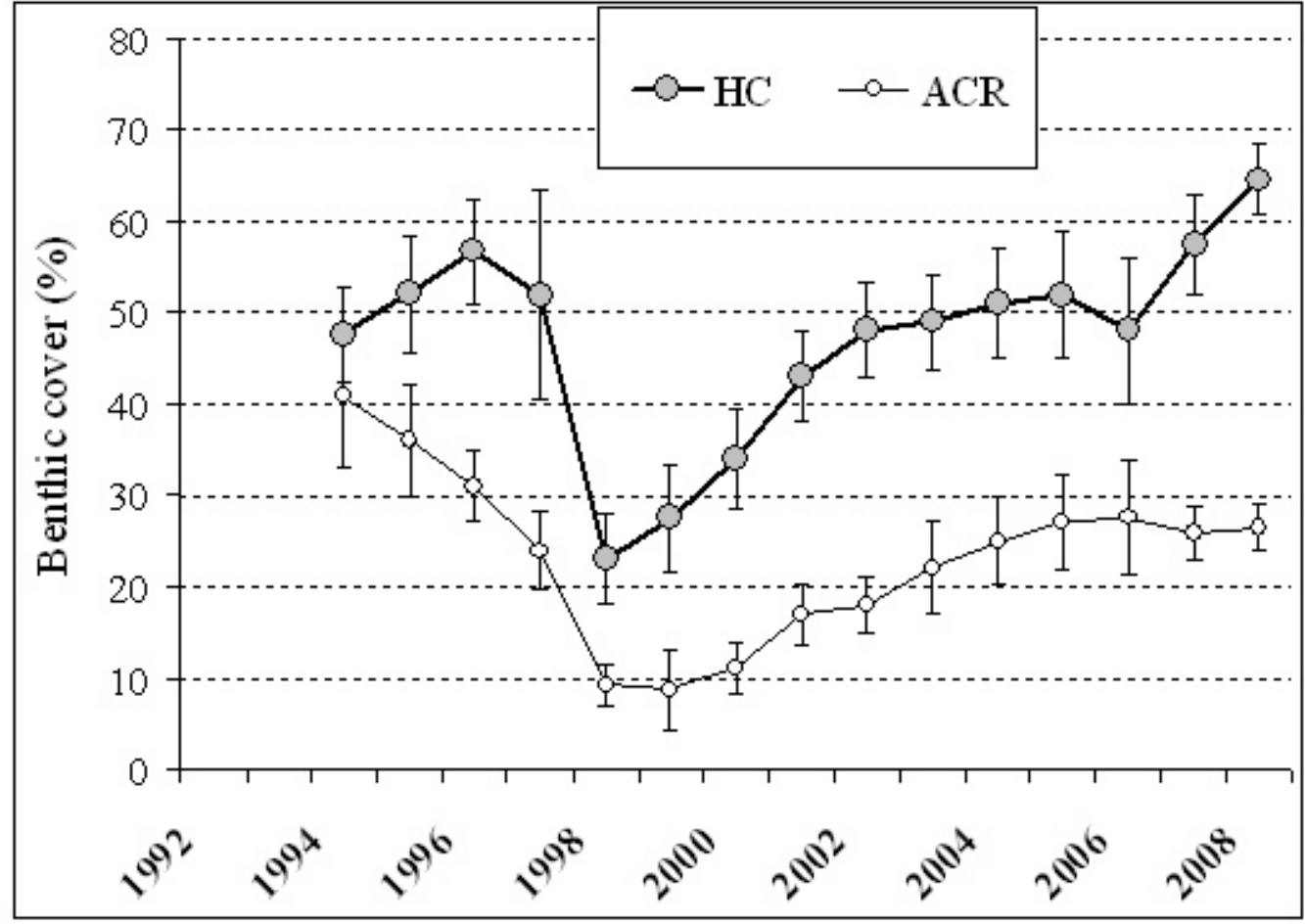

Fig. 3b. Long term trends in total live coral (HC) and Acropora cover in Chumbe, Zanzibar. Note: Sharp decline in 1998/99 was due to bleaching event. Unlike in Bawe, Crown-of-thorns starfish removal program at Chumbe prevented the decline of Acropora cover from 2002 


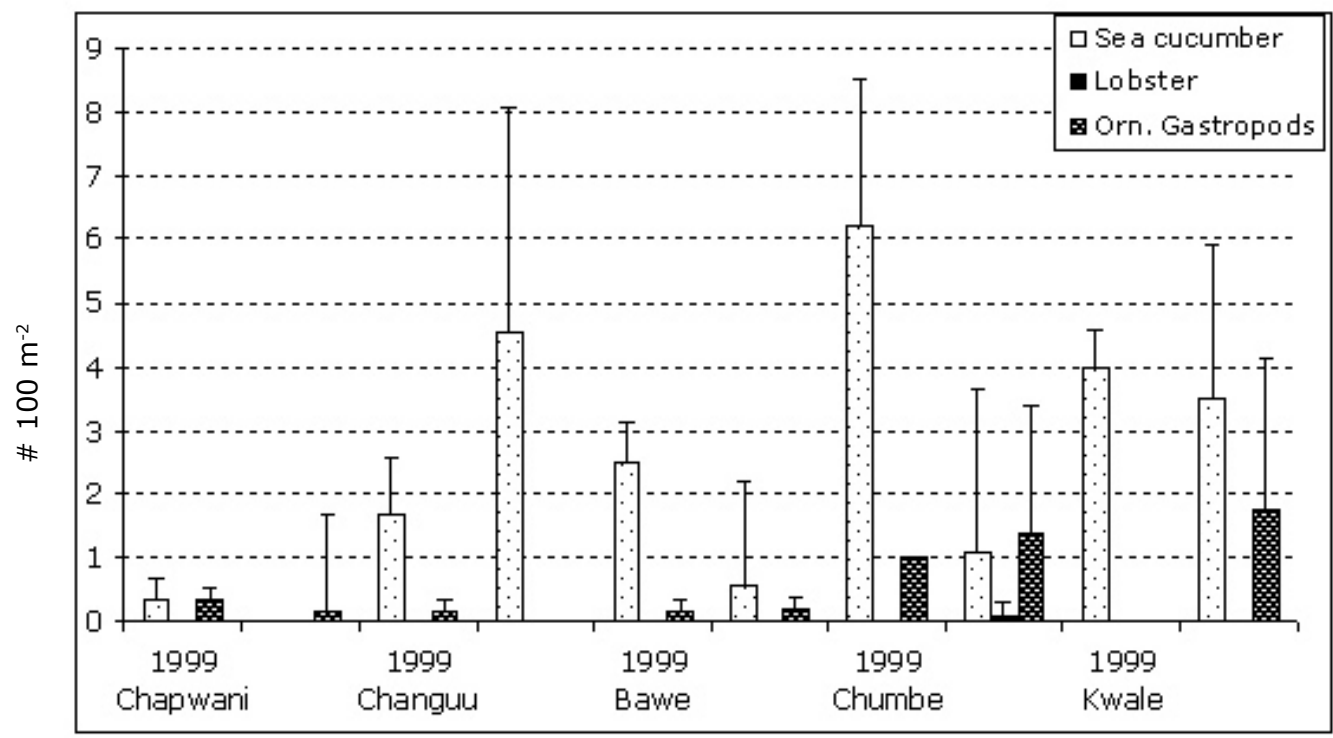

Fig. 4. The average density (per $100 \mathrm{~m}^{-2}$ ) of commercial invertebrates: sea cucumbers, lobsters and ornamental gastropods (shelled molluses) on five reef sites in Zanzibar in 1999 and 2006. Errors bars represent positive standard errors. Note that lobsters were encountered only on Chumbe reef

collected so far suggests the need for a much greater sampling effort. For example, benthic cover sampling in Kitutia, Mafia, in 2003 showed that a minimum of 120 Lineintercept transects (LIT) were required in order to detect $10 \%$ change in coral cover (Table 2). Similarly, more than 92 LIT were required in Mnemba and 138 in Chumbe, Zanzibar (Table 2). The current sampling effort of 9-16 samples is adequate in detecting more than $30 \%$ change (Table 2). The most abundant categories required less sampling effort compared to those that are rare. Such higher sampling efforts are not easily attainable and various techniques, including reducing the size of permanent monitoring plots and increased replications (shorter LIT, are being undertaken to improve effort. The high environmental noise (or variance) on existing CRM datasets is a problem for managers wishing to use monitoring data for management and is a challenge to scientists involved in CRM.
On the other hand, when CB-CRM monitors measured benthic categories on one transect during the calibration process in Tanga, the variance between monitors was low (within acceptable limits) (Muhando, 2008b), indicating that with frequent training and calibration, monitors error is manageable.

Feedback from some ICM managers indicated that some key reef health indicator parameters, e.g. habitat complexity and environmental forcing variables (drivers) such as nutrients dynamics, fishing pressure and sedimentation levels are not measured. Appropriate selection and grouping of reef indicators (categories) for optimum reef management is still needed. Similarly, change in coral reef biodiversity was not well captured. For example, it is not possible to deduce change in coral species richness or differential species resilience in the existing datasets of coral growth forms and broader invertebrate taxonomic groups. The fact that coral reef monitoring started when 
Table 2. The number of transects necessary to detect $10 \%$ (N1) (or Power of $90 \%$ ) and $30 \%$ (N2) (or Power of $70 \%$ ) change, when $\alpha$ (type I error) is 0.05 , assuming no significant change in standard deviation (SD) in subsequent years. Sample sizes (20 $\mathrm{m}$ Line-intercept transects) were: Kitutia, Mafia 2003 n=16; Mnemba 2007 n=11; Chumbe 1999, $n=12$

\begin{tabular}{lcccc}
\hline Kitutia, Mafia & Mean (\%) & SD & Sample size (N1) & Sample size (N2) \\
\hline Hard coral & 17.6 & 6.9 & 120 & 9 \\
Fleshy Algae & 44.9 & 10.1 & 43 & 4 \\
\hline Mnemba, Zanzibar & Mean & SD & N1 & N2 \\
\hline Acropora & 6.2 & 3.1 & 214 & 13 \\
Non-Acropora & 20.7 & 6.8 & 92 & 6 \\
Fleshy algae & 18.2 & 8.3 & 178 & 11 \\
Soft corals & 6 & 4 & 381 & 23 \\
Sponges & 0.5 & 0.5 & 856 & 52 \\
\hline Chumbe, Zanzibar & Mean & SD & N1 & N2 \\
\hline Hard coral & 27.5 & 14.4 & 235 & 14 \\
Acropora & 8.6 & 3.5 & 142 & 9 \\
Non-Acropora & 18.9 & 9.8 & 234 & 74 \\
Other algae & 18.3 & 6.9 & 122 & 145 \\
Soft Corals & 0.6 & 1 & 2379 & 46 \\
Sponges & 1.6 & 1.5 & 732 & \\
\hline
\end{tabular}

the environment was already under stress, provides a challenge in establishing the true baseline condition of coral reef biodiversity and structure. Changing baselines and the concept of functional groups and species resilience is only beginning to be perceived and hence was not considered in the ongoing coral reef monitoring programs.

Administration and coordination of coral reef monitoring outputs at national level in Tanzania is still not optimal. Capacity building lacked continuity and there was a problem of shifting of trained monitors. CRM data is not centralized (no national database) and there is no national strategy to rectify this situation. Similarly, there are weak or no procedures for tracking data and reports from opportunistic reef observations by students and visiting scientists; hence, potential management information was not fully captured. Dissemination of CRM data and information was far from optimum and the situation was aggravated by lack or inconsistency in financial support at national level. When reports were distributed, some MPA managers had problem understanding scientific terminologies and implications of changes in the monitored indicators, hence could not translate data into management practice.

In conclusion, the current CRM program has increased awareness, enhanced conservation efforts and contributed knowledge on the coral reef environment, resources and associated factors/processes. However, the current CRM effort is too sparse (few sites), inconsistent and unable to detect changes at satisfactory levels, hence it should be improved by taking into consideration current management needs, field conditions as well as the participation of scientists, local communities and recreational divers. 


\section{RECOMMENDATIONS}

i) For optimum utilization of CRM data and information both ecological and socio-economic monitoring of coral reefs should be part of a wider ICM programme. In this way, results could be integrated, linked and associated with other coastal ecosystems and the socio-economic condition of coastal communities and vice versa.

ii) Existing CRM programs need to be reviewed and improved to solve ICM issues by:

- Increasing change detection levels by improving sampling design and increasing sampling efforts;

- Designing the optimum (better) combination of CRM protocols to meet the ICM information needs for each coral reef area;

- Including biodiversity (e.g. genus level monitoring for SB-CRM and more parameters for $\mathrm{CB}-\mathrm{CRM}$ ) and reef complexity change indicators;

- Preparing better illustrations (in local language, e.g. Kiswahili) to improve data capture and information dissemination among local community, managers and others;

- Including coral recruitment and/or recovery indicators in communitybased monitoring; and,

- Identifying and measuring important environmental and human indicator factors, e.g. water temperature, nutrient, sedimentation, chlorophyll, fishing intensity, land sources of pollution as part of the coral reef monitoring program.

iii). Data analysis (indicator groupings), storage and reporting should be strategic and encompassing (integrating) other natural sciences, social and economic factors around the monitored sites. iv). In consultation with Central Government, Local Authorities, Regional CRTF, GCRMN, ICM programs, willing donors, etc., secure sustainable funding and ensure continuous capacity building (personnel) and equipment (availability).

v). Active participation of communitybased monitors and scientists in environmental awareness and education should be encouraged further. Conservation knowledge if imparted to teachers and school children, e.g., in Chumbe Island education program, has far reaching impacts.

Acknowledgment-I am grateful to Institute of Marine Sciences, University of Dar es Salaam and the GEF-Coral Reef Targeted Research and Capacity Building for Management Program for facilities offered during this work. I am also thankful to Prof Sven Beer and anonymous referees for valuable comments on the manuscript.

\section{REFERENCES}

English, S., Wilkinson, C. \& Baker, V. (1997) Survey Manual for Tropical Marine Resources, Australian Institute of Marine Science, Australia. 390 pp.

Horrill J.C., Kalombo H \& Makoloweka S. (2001) Collaborative reef and reef fisheries management in Tanga, Tanzania. IUCN EA Program, Nairobi. 37 pp.

Horrill, J.C. \& Ngoile, M.A.K. (1991) Results of the physical, biological and resource survey; rationale for the development of a management strategy. Marine Parks and Reserves Unit. Dar es Salaam.

Horrill, J.C., Machano, H. \& Omar, S.H. (1994a) Misali Island: Rationale for a marine protected area. Commission for Lands and Environment, Zanzibar. Zanzibar Environment Study Series No. 17. 20 pp.

Horrill, J.C., Machano, H. \& Omar, S.H. (1994b) Baseline monitoring survey of coral reefs and fisheries of the Fumba peninsula, Zanzibar. Commission for Lands and Environment. Zanzibar. Environmental Study Series, No. 16. 9 pp. 
Ireland, C, Mellaret D. \& Baker, L. (2004) Alternative sustainable livelihoods for coastal communities $-A$ review of experience and guide to best practice. IUCN, Nairobi. $75 \mathrm{pp}$.

Jiddawi, N.S. and Stanley, R. (eds.) (1997) Fisheries Stock Assessment in the traditional Fishery Sector: The information needs. Proceedings of the National Workshop on the Artisanal Fisheries Sector. September 1997, Zanzibar. IMS. 192 pp.

Johnstone, R., Muhando, C. \& Francis, J. (1998) The status of coral reef of Zanzibar: One example of a regional predicament. Ambio, 27: 700-707.

Malleret-King, D. Glass, A. Bunce, L. \& Pomeroy, B. (2006) Socioeconomic Monitoring Guidelines for Coastal Managers of the Western Indian Ocean. CORDIO East Africa Publication (version 1). 108 pp.

Mbije, N.E.J.(2005)Integrated assessment of suggested collaborative fisheries management (CFM) areas in Bagamoyo. Tanzania Coastal Management Partnership. TCMP/CRC Report. 25 pp.

McClanahan, T., Ateweberhan, M., Graham, N., Wilson, S.K., Ruiz-Sebastian, C., Guillaume, M.M. \& Bruggenmann, J.H. (2007b). Western Indian Ocean coral communities: Bleaching responses and susceptibility to extinction. Marine Ecology Progress Series, 337:1-13

McClanahan, T., Ateweberhan, M., Muhando, C., Maina, J. \& Mohammed, M.S. (2007a) Effects of Climate and Seawater Temperature Variation on Coral Bleaching and Mortality. Ecological Monographs 7: 503-525.

McClanahan, T.R., Muthuga, N.A. \& Mangi, S., (2001) Coral and algal changes after the 1998 coral bleaching: interaction with reef management and herbivores on Kenyan reefs. Coral Reefs, 19: 380-391.

Mohamed, A., Mohammed, M.N. \& Richmond, M.D. (2007) Bahari yetu: Kitabu cha Mwongozo wa Maisha ya Viumbe wa Baharini Afrika Mashariki. SAMAKI Arts, Jamana Printers, Dar es Salaam. 91 pp.

Mohammed, M.S., Muhando, C.A. \& Machano, H. (2000) Assessment of coral reef degradation in Tanzania: Results of coral monitoring 1999. In: Souter, D., Obura, D., and Linden, O. (eds.) 2000. Coral Reef Degradation in the Indian Ocean: Status Report 2000. CORDIO. pp 35-42.
Mohammed, S.M., Muhando C.A. \& Machano, H. (2002). Coral Reef Degradation in Tanzania: Results of Monitoring 1999-2002. In: O. Linden, D. Souter, D. Wilhelmsson, \& D. Obura (Eds.), Coral Reef Degradation in the Indian Ocean. Status Report 2002 (pp. 108). Kalmar: CORDIO. pp 21-30.

Muhando, C.A. (1995) Ecological consideration of Menai Bay, Zanzibar. A feasibility study report for the establishment of Menai Bay (Fumba) community based conservation area. In: Ngoile, M.A.K. and Sichone, W. (eds.), Proceedings of the Workshop on the Conservation of Menai Bay, Zanzibar. 2-4 May, 1995. The paper appears as a separate annex to the proceedings. $22 \mathrm{pp}$.

Muhando, C.A. (1999) Assessment of the extent of coral damage, socio-economics effects mitigation and recovery of coral reefs in Tanzania. In: Linden, $\mathrm{O}$ and Sporrong $\mathrm{N}$ (eds). Coral Reef Degradation in the Indian Ocean: Status report and project presentation. CORDIO, Stockholm. pp 43-47.

Muhando, C.A. (2006) Ecological Monitoring of Coral Reefs in Marine No-Take and Fished Zones off Bagamoyo Coast. TCMP/CRC Report. 35 pp.

Muhando, C.A. (2008a) Approaches to Coral Reef Monitoring in Tanzania. In: Obura, D.O., Tamelander, J., \& Linden, O. (Eds) (2008). Ten years after bleaching - facing the consequences of climate change in the Indian Ocean. CORDIO Status Report 2008. CORDIO. pp 129-138.

Muhando, C.A. (2008b) Calibration of Community Based Coral Reef Monitoring Protocols: Tanzania Case Study. Western Indian J. Mar. Sci. (Accepted).

Muhando, C.A., Kuguru, B.L., Wagner, G.M., Mbije, N.E. \& Ohman, M.C. (2002) Environmental effects on the distribution of corallimorpharians in Tanzania. Ambio 31: 558-561.

Muhando C.A. and Mohammed S.M. 2002. Coral reef benthos and fisheries in Tanzania before and after the 1998 coral bleaching and mortality event. Western Indian Ocean J. Mar. Sci., 1: 43-52

Muhando, C.A., Ong'anda H. \& Bydekeke, L. (2004) Physical alteration and Destruction of Habitats (PADH): Overview of Physical and Destruction of Habitats in the Eastern African Region using Geographical Information System (GIS). UNEP/GPA/WIOMSA Report. 87 pp. 
Ngoile, M.A.K. (ed.) (1990) Ecological Baseline Surveys of Coral Reefs and Intertidal Zones around Mnemba Island and Zanzibar Town. Zanzibar Environmental Study Series no. 8.87 pp.

Obura, D. (2004) Biodiversity surveys of the Coral Reefs of the Mnazi Bay and Ruvuma Estuary Marine Park. IUCN EARO - Nairobi). vi + 72 pp.

Raymundo L.J, Couch C.S, and Harvey, D. (eds.) 2008 Coral Disease Handbook. Coral Reef Targeted Research and Capacity Building for Management Program. 121 pp.

Richmond, M.D, (ed.) (1997) A field guide to the shores of Eastern Africa and the Western Indian Ocean Islands. Sida-SAREC. $448 \mathrm{p}$

Scheuer, P.J. (2006) From the rainforest to the reef: Searching for bioactive natural products in the mid-pacific. Medicinal Research Reviews, 14(5): $487-503$

Souter, D. \& Linden, O. (2005) Coral Reef Degradation in the Indian Ocean Status Report 2005. CORDIO. 285 pp.

TCMP (2001) Tanzania Coastal Tourism Situation Analysis. TCMP Working Document no. 5057. $51 \mathrm{pp}$.
UNEP (1989) Coastal and marine environmental problems of the United Republic of Tanzania. UNEP Regional Seas Reports and Studies No. 106. 33 pp. + annex.

Ussi, A.M. 2008 Population Dynamics and Impact of Crown-of-Thorns Starfish, Acanthaster planci (L), on Coral Reefs of Zanzibar. MSc Theses, University of Dar es Salaam. 93 pp.

Wagner, G M. (2004) Coral Reefs and Their Management in Tanzania. Western Indian Ocean J. Mar. Sci. 3: 227-243.

Wells, S., Makoloweka, S. and Samoilys, M. (eds.) 2007 Putting Adaptive Management into Practice: Collaborative Coastal Management in Tanga, Northern Tanzania. IUCN, Nairobi; Kenya. $197 \mathrm{p}$.

Wilkinson, C. (ed.) (2004) Status of Coral Reefs of the World: Australian Institute of Marine Science. 557 pp.

Wilkinson, C., Green, A., Almany, J. \& Dionne, S. (2003) Monitoring Coral Reef Marine Protected Areas: A Practical Guide on How Monitoring Can Support Effective Management of MPAs. Australian Institute of Marine Science and the IUCN Marine Program. 68 pp. 